\title{
Atravessamentos alquímicos na Psicologia
}

\section{Alchemical crossings in Psychology}

\author{
Helton Marculino de Souza ${ }^{1}$
}

\begin{abstract}
Resumo
Objetiva-se, com o presente artigo, discutir as contribuições da Alquimia para o campo da Psicologia, em especial para a Psicologia Analítica como proposta de uma Psicologia Alquímica, cujos representantes aqui destacados são Carl Gustav Jung e James Hillman. Entende-se que os conhecimentos da Alquimia foram aplicados em áreas diversas, tais como metalurgia, química, filosofia, tendo uma aplicação possível no campo da Psicologia. Neste sentido, observa-se que, se para Jung os conceitos da Alquimia tecem conexões com os saberes propostos pela Psicologia Analítica, por outro lado Hillman se apropria destes conhecimentos para desenvolver uma estratégia para utilização no campo da psicoterapia, propõe raciocinar alquimicamente. Assim, para este segundo autor, no exercício da Psicologia, os encontros com o paciente vão além da aplicação de teorias, constituindo-se como um "fazer-alma" no consultório. Isto é, mais do que traduzir símbolos, propõe-se o "ficar com a imagem", com uma atenção tanto do paciente quanto do psicólogo para que as palavras expressas nesse diálogo não se tornem "palavras-coisas" ou sejam reduzidas a um significado único, que tende a inutilizar a imagem. Espera-se, por meio deste trabalho, fomentar o conhecimento dos profissionais acerca da Psicologia Analítica e Psicologia Alquímica, em suas conexões com a Alquimia e suas reverberações no campo da psicoterapia nestas abordagens.
\end{abstract}

Palavras-chaves: Psicologia analítica. Alquimia. James Hillman.

\begin{abstract}
The objective of this article is to discuss the contributions of Alchemy to the field of Psychology, especially for Analytical Psychology as a proposal of an Alchemical Psychology, whose representatives highlighted here are Carl Gustav Jung and James Hillman. It is understood that the knowledge of Alchemy have been applied in various areas such as metallurgy, chemistry, philosophy, and it has a possible application in the field of Psychology. In this sense, it is observed that if to Jung the concepts of Alchemy interlace connections with the knowledge proposed by Analytical Psychology, on the other hand Hillman adopts this knowledge to develop a strategy for use in the field of psychotherapy, proposing to think alchemically. Thus, for this second author in the exercise of Psychology, the meetings with the patient go beyond the application of theories, constituting as a "do-soul" in the office. This is, more than translating symbols, it is proposed to "stay with the image", with an attention from both the patient and the psychologist for that the words expressed in this dialogue does not become "wordthings" or be reduced to a unique meaning that tends to discard the image. It is hoped, through this work, to promote knowledge of the professionals about the Analytical Psychology and Alchemy Psychology in their connections with Alchemy and its reverberations in the field of psychotherapy in these approaches.
\end{abstract}

keywords: Analytical psychology. Alchemy. James Hillman.

\footnotetext{
${ }^{1}$ Graduado em Psicologia pelo Centro Universitário Hermínio Ometto - UNIARARAS. E-mail: helton.marculino@gmail.com
} 


\section{Introdução}

A Alquimia pode ser considerada como um campo composto por diversas teorias relacionas à matéria e composição de substâncias inanimadas e viventes. Já foi, ademais, considerada um sistema filosófico que procurava conhecer os mistérios da criação da vida, com busca por aperfeiçoar a vida a partir de sua natureza. Por fim, pode-se entender que a Alquimia mostra-se também como a origem da química (READ, 1951).

Segundo Lima e Silva (2003, p. 22), não há precisão sobre o início da Alquimia. Esta pode ser observada em diferentes tradições do mundo antigo, que foram transmitidas por vias orais ou textos herméticos compostos de "operações químicas, misticismo, magia, filosofia, astrologia". Neste sentido, nota-se a ligação com os primórdios da metalurgia, nos processos de cura de metais pelo fogo, com o intuito de alteração de seu estado. Exemplifica-se esta ligação entre Alquimia com metalurgia por meio da concepção alquímica da Mãe Terra, entendendo-a como aquela que gesta metais a partir de um processo de desenvolvimento que passa pelo cobre, chumbo, estanho, metais esses que possuem os mesmos elementos como enxofre e mercúrio. A criação destes metais é compreendida como um "processo abortivo", por meio do qual se tem a obtenção de outros minerais menos nobres, sendo que o fim da "gestação" é marcado pela produção do ouro. O intuito da Alquimia configurava-se em estudar formas de acelerar tal “gestação" na busca de minérios mais puros como o “ouro, prata e platina” (LIMA; SILVA, 2001, p. 23). Almejava-se obter um produto que, ao ser lançado sobre o metal em fusão, pudesse acelerar o processo embrionário de mineral para metal gestado pela Mãe Terra.

Dentro do campo filosófico, os Alquimistas passaram a apresentar a ideia de que, assim como os metais impuros poderiam alcançar a perfeição, os seres humanos sendo parte da natureza também poderiam alcançar a perfeição. Neste sentido, assim como há "tortura" pelo fogo no campo dos metais, a tortura na vida humana aconteceria pela via do sofrimento, vida esta que se purifica no decorrer de muitas etapas. Com isso, este processo passa a ser representado a partir da figura de uroboro (a serpente ou dragão que engole a própria cauda).

A Alquimia, permeando assim variadas culturas e por diversos períodos, passa a se constituir de distintos elementos em sua existência, tais como símbolos, códigos, figuras e escritas hieroglíficas, conceitos orientais de equilíbrio como ying, yang, feminino - lua, masculino - sol. Propõe a busca do elixir, um fermento de transformação capaz de produzir o equilíbrio entre o ser humano e o cosmos, sendo esse denominado de "Divino Cinábrio"”, e assim alcançar a longevidade e imortalidade.

Para os alquimistas, a cura era obtida através de um retorno às origens: reviver a criação permitia o renascer. A Alquimia passou por diversas tensões com movimentos de apropriação deste conhecimento e outros de destruição do mesmo. Entendia-se que, sendo a Alquimia de alguma forma preciosa, não poderia estar acessível a qualquer um. Construiu-se, portanto, um processo por meio do qual somente os iniciados poderiam entender seus ensinamentos, com um desejo de diversas áreas por se apropriar deste saber, aspecto percebido tanto no campo médico como no campo filosófico, como defendia o filósofo Roger Bacon. Apesar da visão alquímica ter contribuído para diversas vertentes do conhecimento e sobrevivido à Idade Média, à Igreja e à inquisição, bem como ao início da ciência moderna, ela passou a perder força no campo científico (LIMA; SILVA, 2003). Deixou, porém, muito a ser explorando como área mais ampla do saber, dentre essas contribuições objetiva-se aqui

\footnotetext{
${ }^{2}$ Para a alquimia chinesa é uma operação que realiza simbolicamente a regeneração e imortalidade física (LIMA; SILVA, 2003).
} 
demarcar o tom "filosófico" dado pela Alquimia e sua contribuição para a Psicologia.

A interlocução entre Psicologia e Alquimia é observada em alguns momentos da História da Psicologia, sendo que alguns exemplos são apontados pelo psicanalista Herbert Silberer, por Carl Gustav Jung e por James Hillman, proponente da uma visão por ele denominada como Psicologia Alquímica. A despeito de sua ligação com a Psicologia Analítica, abordagem amplamente conhecida e discutida no cenário nacional, nota-se que poucos são os textos que versam sobre o percurso e sobre a especificidade das ideias de Hillman. Diante deste cenário, o presente artigo objetiva-se discutir as contribuições da Alquimia para o campo da Psicologia, em especial para a Psicologia Analítica como proposta de uma Psicologia Alquímica. Almeja-se, ademais, apontar para processos que permeiam a prática clínica nestas abordagens, fomentando o conhecimento de interessados na área.

\section{Psicologia Analítica e Atravessamentos Alquímicos}

A Psicologia Analítica é uma vertente teórica criada por C. G. Jung, psiquiatra suíço tido inicialmente por Freud como a esperança de continuidade da psicanálise, mas que rompeu, posteriormente, com essa expectativa por questionar e propor novas questões ligadas principalmente ao conceito de libido e sexualidade. Contudo, mesmo havendo tal rompimento, alguns aspectos da ciência psicanalítica permaneceram como base para métodos e conceitos propostos por este autor.

Certamente a hipótese de Freud, ainda que parcial, foi assim mesmo um avanço libertador para a criação de uma psicologia das conexões psíquicas. Sua obra é precisamente uma psicologia das ramificações do instinto sexual na alma humana. Não obstante a importância inegável da sexualidade, contudo não se pode admitir que toda e qualquer coisa dependa desse instinto. (JUNG, 1981, p. 86)
Os laços entre Jung e Freud foram desfeitos de forma gradativa. Jung (1975) em sua última obra "Memórias, Sonhos e Reflexões" menciona que o rompimento com Freud iniciou-se em 1909, em uma viagem que fizeram juntos aos Estados Unidos para as comemorações do ducentésimo aniversário da Universidade Clark. Posteriormente, em 1912, as diferenças nas ideias entre ambos autores se amplia com a publicação do artigo "Metamorfoses e símbolos da libido", título depois alterado para o, então, conhecido "Símbolos da Transformação", que marca historicamente o "rompimento".

Quanto ao termo "Psicologia Analítica", este foi mencionado pela primeira vez por Jung em 1913, no "IV Congresso Internacional de Psicanálise", em Viena, como forma de "explicar" as diferenças entre a visão de Freud e Jung. Em 1914, Jung deixa a presidência da Associação Psicanalítica Internacional, passando assim a dar consistência ao que posteriormente foi denominada de Psicologia Analítica. Jung não tinha pretensão de criar uma nova abordagem que acarretasse seguidores, fato que aparece em uma de suas cartas em 1946, quando indica "Só espero e desejo que ninguém se torne junguiano. Eu não represento nenhuma doutrina, mas descrevo fatos e apresento certos pontos de vista que julgo merecedores de discussão" (JUNG, 2002, p. 9). Jung foi um grande estudioso e curioso em diversas áreas, como astronomia, artes, Alquimia, as quais contribuíam com sua visão de mundo.

Barcellos (HILLMAN, 2011) na nota de tradução do livro "Psicologia Alquímica" de James Hillman, comenta que no percurso da Psicologia Analítica, Jung encontra na Alquimia a possibilidade de escapar do excesso de subjetividade, "o subjetivismo", sendo a Alquimia um ponto de vista objetivo ao que Jung havia denominada de psique objetiva. Em relação à contribuição da Alquimia para a obra de Jung, o mesmo relata: "Vi logo que a psicologia analítica concordava singularmente com a Alquimia. Para mim, isso foi naturalmente uma descoberta ideal, uma vez que percebi a conexão histórica da psicologia do inconsciente." 
(JUNG, 1975, p. 181). Jung observou o que havia entre Alquimia e Psicologia profunda, entendendo projetivamente os conteúdos psíquicos presentes nos tratados alquímicos, de forma a contribuir com os conceitos de alma.

Quanto ao conceito de alma, tem-se um entendimento desta, na Psicologia Analítica, como a subjetividade do indivíduo, sendo, a relação do indivíduo com o mundo, algo exclusivo ou subjetivo a ele. Hillman (1995, p. 17), ao referirse sobre a definição de alma, indica que "Quando tentamos defini-la, afastamo-nos da sua natureza indefinível [...]". Dessa forma, somente o contato em cada momento com a alma é que pode "falar" dela, porém não defini-la de forma generalizada. Por exemplo, uma receita culinária pode resultar no mesmo produto final determinado pela receita, contudo o sabor nunca será idêntico.

Em 1928, Richard Wilhelm, um importante sinólogo enviou a Jung o texto do "O segredo da flor de Ouro", livro de Alquimia chinesa que despertou em Jung o desejo de conhecer os alquimistas. Tal interesse foi decorrente da relação de Jung com símbolos, tendo encontrado bases nesse texto, vindo posteriormente a participar do prefácio do livro de Wilhelm.

O Segredo da Flor de Ouro constitui um tratado alquímico, além de ser um texto taoísta da ioga chinesa. Um estudo posterior e aprofundado dos tratados latinos me esclareceu e demonstrou que o caráter alquímico do texto tinha um significado essencial. Não é este, porém, o lugar adequado para estender-me acerca de tal ponto. Quero apenas sublinhar o fato de ter sido o texto da Flor de Ouro que me ajudou a encontrar a via correta. A alquimia medieval representa o traço de união entre a gnose e os processos do inconsciente coletivo que podem ser observados no homem de hoje (JUNG, 1977, p. 5).
Após aprofundamento sobre o tema, por volta dos anos 1940, Jung produziu importantes trabalhos ligados aos símbolos tanto religiosos quanto alquímicos. Nesse período, dado o desenvolvimento da Psicologia Analítica, é fundado o "Instituto C. G. Jung de Zurique". Assim como Jung aproximouse de Freud, muitos aproximaram-se de Jung com o objetivo de contribuir com a Psicologia Analítica. Contudo, como mencionado anteriormente, Jung sempre deixou claro que não gostaria de ter discípulos, os então denominados "junguianos", mas sim pessoas que continuassem o pensamento ao invés de repeti-los.

A partir desta proposta de continuidade do pensamento, tem-se o trabalho do psicólogo James Hillman, que traz a atenção para a Psicologia Arquetípica de Jung e para um fazer alquímico da Psicologia. Este autor propõe um raciocinar alquimicamente em Psicologia, por utilizar as metáforas alquímicas em seus textos, justificando que a linguagem do inconsciente é metafórica sendo assim possível apropriar-se de tal linguagem para a compreensão do psiquismo.

Hillman concebe a Psicologia Alquímica como a "poiesis da matéria" (HILLMAN, 2011), devido à linguagem poética observada na Alquimia, forma essa também compreendida como a linguagem do inconsciente e da Alquimia, uma "psicopoiesis" (HILLMAN, 2011). Hillman atenta-se a não simplesmente traduzir símbolos, mas manter o princípio que Jung (1990) que sugere "ficar com a imagem $^{3 "}$. Destaca-se que o mesmo termo referese à máxima grega de "salvar os fenômenos" forma que a imaginação sensível é alvo de atenção da Psicologia, que apresenta seus estados na mente do indivíduo, similar à perspectiva epistemológica a qual apresenta-se verdades. Observa-se, assim, que

\footnotetext{
${ }^{3}$ A teoria de Jung, em sua concepção, refere-se a uma base poética da mente exercida na imaginação ativa. Sendo assim, nos processos de imaginação, a psique cria uma realidade para si. Neste sentido, "ficar com a imagem" refere-se a uma posição ética em relação à imagem, de modo a "ouvi-la" e não apenas classificá-la.

${ }^{4}$ Salvar os fenômenos em relação à astronomia grega significa não interferir nas causas do fenômeno ou discutir sua natureza (LOSSE, 1998).
} 
não há apenas uma única verdade para o fenômeno. Segundo Jung (1991, p. 417), a imagem é "uma representação imediata, oriunda da linguagem poética, ou seja, a imagem da fantasia que se relaciona indiretamente com o objeto externo".

Observa-se uma similaridade entre os fenômenos da Alquimia com a Psicologia, no que concerne à reação da matéria de acordo com o estado em que se apresenta e ao que é submetido durante o processo. Hillman (2011) apresenta a linguagem alquímica como terapêutica e destaca seu potencial no campo da neurose. Nestes casos, tem-se um padrão de organização da personalidade consciente que pode ser trabalhado de forma interessante por meio desta linguagem alquímica, ou seja, aquela que faz um uso de metáforas pertinentes a cada situação e não de maneira reducionista.

No livro Psicologia Alquímica, de James Hillman (2011), apresenta-se um questionamento "filosófico" a princípio sobre o uso da linguagem, por trazer à reflexão os discursos psicológicos, permeado por termos e conceitos, utilizados pela "comunidade de psicólogos" para fundamentarse. Hillman atenta para uma possível "ilusão" teórica sobre a prática, com os psicólogos podendo "cair na armadilha" do literalismo da própria linguagem. Neste sentido, indica-se a tendência a pensar como "palavras-coisas", lembrando que alguns termos foram desliteralizados, como Freud fez ao falar de trauma sexual, apresentando assim o complexo de Édipo, assim como Jung fez com o conceito de libido. Dessa mesma forma, fala-se de ego, inconsciente, dentre outros termos que são literalizados. O psicólogo não vê o ego do indivíduo, mas o literaliza para falar do mesmo.

Um questionamento pertinente a esta visão seria: se os sonhos são material do inconsciente, por que ao interpretá-lo utiliza-se outra linguagem? Em um sonho, por exemplo, podemos sonhar que estávamos em um estado febril, mas não pensamos ou dizemos que estamos a $37,8^{\circ} \mathrm{C}$ (temperatura considerada pela ciência como o estado febril). Assim também se apresenta a Alquimia, por descrever o fenômeno a partir de si, e não através de uma linguagem adaptada a explicar o fenômeno. Quando a Alquimia se refere a níveis de calor, não utiliza números. Refere-se por exemplo à temperatura do nascer do sol na primeira manhã de primavera ou à temperatura do estrume do cavalo, à temperatura do metal tocando o fogo, apresentando assim a temperatura não somente em níveis mas também em qualidade, de forma que o calor pode ser "lento e brando, ou úmido e pesado, ou súbito e agudo.” (HILLMAN, 2011, p. 24).

Portanto, a Alquimia passa a ser terapêutica por "forçar" a metáfora na linguagem, visto ser essa a linguagem do inconsciente na concepção da Psicologia Alquímica. Nos textos alquímicos, o leitor deve esforçar-se, entregar-se para compreender o sentido, "a pedra escondida". Seu vocabulário não define características singulares dos fenômenos, convida assim a vivenciar tal fenômeno a partir de cada singularidade. Nas palavras de Hillman (2011, p. 28-29):

"Este é o efeito terapêutico da alquimia: ela força a metáfora sobre nós. Somos carregados pela linguagem para dentro de um como-se, para dentro tanto da materialização da psique quanto da psiquização da matéria ao pronunciarmos nossas palavras."

O que Hillman (2010) chama de nominalismo refere-se à descrença nas palavras, de maneira que o fato de saber que "tem-se" um ego, self ou um instinto de poder ou que passou-se pela castração, passa a ser puramente ou simplesmente palavras. Destaca-se a pretensão da Psicologia Alquímica em não falar simplesmente de Alquimia, mas falar como os alquimistas, falar alquimicamente, por não simplesmente trocar os termos, mas sim propor um retorno literal à Alquimia, ao modo alquímico de imaginar, de maneira "a restaurar a matéria imaginativa, não a Alquimia literal [...] Como podemos ter fé no que fazemos se as palavras que usamos para isso são desincorporadas de substância?" (HILLMAN, 2011, p. 31). 
Nossa fala está "contaminada" pelo cientificismo sociológico e econômico de forma que, segundo Hillman (2011), fizeram por perder a fé no poder da palavra. Assim, a Psicologia passou a olhar os gestos e linguagens corporais, sendo necessário um resgate da linguagem, um retorno ao discurso. Tal autor sugere também o retorno ao filósofo Confúcio, por dizer que a terapia da cultura começa com a retificação da linguagem. Deste modo, a Psicologia Alquímica apresenta-se como possibilidade no consultório.

\section{A prática clínica na Psicologia Alquímica: Breves Discussões}

Jung observou as bases de seus fundamentos para Psicologia em relação à questão simbólica abarcada na Alquimia e a similaridade dessas no histórico do inconsciente como meio para estruturar as bases dos conceitos de imagem, arquétipos e inconsciente coletivo (JUNG, 2002). Já Hillman (2011) apresenta um outro olhar sobre a Alquimia, por vê-la como potência no uso terapêutico. Entendia que, se a mesma utilizava de inspirações e metáforas diferentes dos métodos da ciência moderna, por que não resgatar esses elementos presentes na natureza humana como forma de diálogo.

Neste sentido, no setting terapêutico, o paciente ao buscar relatar o que sente ou descrever determinada situação pode não encontrar palavras que descrevam concretamente o que deseja comunicar. Para tanto, o indivíduo utiliza-se de metáforas ou ditados populares, abrindo, deste modo, um leque de possibilidades que pode favorecer o diálogo. Diferente da Psicanálise com o método de associação livre, a terapia analítica propõe apontamentos durante a fala do paciente e, a partir daí, Hillman apresenta a Psicologia Alquímica como um modo de prosseguir com as metáforas apresentadas. Parte-se da ideia que as imagens que compõem a fala metafórica do paciente podem ser compostas de conteúdo do inconsciente individual, que tem características de concepção pessoal, e do inconsciente coletivo, como características comuns observadas estruturalmente na humanidade, sendo estes os arquétipos.

"O arquétipo é um elemento vazio e formal em si, nada mais sendo do que uma facultas praeformandi, uma possibilidade dada a priori da forma da sua representação. O que é herdado não são as idéias, mas as formas, as quais sob esse aspecto particular correspondem aos instintos igualmente determinados por sua forma." (JUNG, 2002, p. 91)

Concebe-se, portanto, que o ser humano não nasce vazio, mas inconsciente. Esses conteúdos estruturais são preenchidos por meio das relações do indivíduo. Os arquétipos possuem relativo grau de autonomia e possuem uma relação com o ego, no qual constela-se um complexo. Acerca disto, Jung (2009) defende que "Toda constelação de complexo implica um estado perturbado de consciência.” (p. 30). Por exemplo, o complexo paterno constela-se no enfrentamento das relações conscientes e inconscientes, ao qual forma-se uma imagem. Essa relação é cercada de sentimentos, afetos que podem ser positivos ou negativos. Geralmente, para se conviver com essa imagem objetiva, pode-se ocultar tudo que é negativo nela para a consciência, por uma cisão de afetos, sendo controlada assim pelo então complexo paterno. O ego diferencia-se como complexo do ego por ter como referência o próprio corpo, esse que possui conexão direta com sensações e coloca o indivíduo em contato concreto com o mundo.

Por essa via histórica de associações, também nota-se a via expressiva dos complexos quando atingem determinados graus de autonomia. Tais emoções por algumas vezes são representadas na fala metafórica ou em sonhos. Estas imagens aparecem nos mitos, nos contos, nos deuses. Tal como para os alquimistas o fogo era de extrema 
importância, assim também era para os deuses mitológicos, que transformavam pelo fogo, puniam, destruíam para construir.

Assim como na Alquimia o controle do fogo é fundamental, no processo terapêutico não seria diferente.

\begin{abstract}
A arte do fogo e a chave da alquimia significam aprender como aquecer, excitar, entusiasmar, inflamar, inspirar o material à mão, que é também o estado de nossa natureza, de forma a ativá-la rumo a um estado diferente.

É claro que o laboratório, o forno, os alambiques e as retortas, os cotrabalhadores são invenções imaginárias tanto quanto fenômenos materializados. Você é o laboratório; você é o vaso e a coisa sendo cozinhada. Assim também o fogo é um calor invisível, lugar arejado e consideração amorosa constante. (HILLMAN, 2010, p. 35)
\end{abstract}

Acredita-se que ao estar em contato com o outro necessitamos sempre de atenção sob a intensidade do contato. Assim como o fogo aquece para uma condição de conforto, também queima gerando desconforto. Ilumina para que seja visto, sendo necessário a administração da distância ideal da substância. Do mesmo modo como há substâncias que podem ser mais ou menos inflamáveis, essas podem surgir conscientes para ambos ou somente para um, sendo esse o psicólogo ou o paciente.

O fogo é um agente nos processos transformadores da Alquimia e posteriormente da química. Como metáfora nos ajuda compreender o processo terapêutico. Assim como a expressão "deixar em banho-maria", nos remete à imagem literal de um recipiente sob o fogo que utiliza a água como intermediário para aquecer a substância de outro recipiente, é um método para um aquecimento lento e vagaroso, um cuidado mais delicado. Para cada substância mostra-se necessário um cuidado diferente para a mudança de estado.

Observa-se que um corpo que já passou pelo fogo, muda de estado. "O corpo calcinado é aquele que passou pelo fogo, um corpo renascido, um corpo sutil, não mais ligado ao que esteve ligado e que, portanto, pode ser inteiramente absorvido pela obra." (HILLMAN, 2010, p. 41). O processo terapêutico como potencialmente transformador requer uma atenção específica a cada indivíduo. Por exemplo, o intervalo entre as sessões que pode variar conforme a demanda de cada pessoa, os diferentes modos pelo quais serão trabalhadas as questões. Dessa forma, é pertinente a atenção do psicólogo em conhecer e estar atento ao "próprio fogo", ou seja, estar sempre atento às próprias questões pessoais envolvidas no processo, bem como buscar conhecer os conteúdos que "passarão" pelo fogo.

"Quando aceleramos a natureza com calor, adaptamos o calor às qualidades da substância. Mais que isso: o calor que aplicamos externamente por meio do fogo visa acender e reforçar o calor inclusus dentro da substância. A quantidade e a qualidade do calor são determinadas pela coisa com a qual estamos trabalhando." (HILLMAN, 2010, p. 48)

Em relação à amplidão do que se pode pensar sobre o fogo, Hillman (2011) pondera que o fogo necessita de combustível. Para os alquimistas o fogo mais puro precisa da substância mais pura. Assim como o carvão vegetal e o ar alimentam o fogo, nota-se que o carvão é puro porque já passou pelo fogo, sendo assim o que lhe é supérfluo já foi queimado pelo fogo. Com isso, o carvão alimenta o fogo sem exigir nada em troca. $O$ ar também deve ser dosado, pois a sua ausência elimina o fogo e seu excesso, seu fluxo, o intensifica, "um fluxo constante de atenção focada aviva o carvão inerte, produzindo quentura e luz.” (p. 51).

Quanto ao tema fogo relacionado às culturas, exemplifica-se que o fogo para os hindus refere-se ao fogo dos mundos, e para outros povos o deus sol é o fogo maior. Nas tradições celtas, o fogo faz parte de elementos rituais. Na Irlanda antigamente havia a festividade de Beltane, na qual acendiam o fogo de Bel e faziam passar o gado por ela 
como prevenção das epidemias (GHEERBRANT; CHEVALIER, 2000).

A imagem transformadora do fogo também é experenciada no setting terapêutico. Segundo Hillman (2010), o fogo deve ser combatido com fogo, não no sentido de exterminar, mas de interagir, o fogo do psicólogo com o do paciente. " $\mathrm{E}$ o alquimista deve ser capaz de combater fogo com fogo, usando seu próprio fogo para operar sobre os fogos com os quais está operando." (HILLMAN, 2010, p. 37). Cada "material" inflama ou incendeia de forma diferente. Reconhecer a sensibilidade de cada um é saber de sua composição, é conhecer sua alma, no sentido de saber como se apresenta em suas relações, principalmente reconhecer que todas as coisas são almadas. Sobre este tema, vale mencionar o que Hillman (2010) aponta sobre a anima mundi:

[...] ao reconhecer as coisas e as ferramentas, os lugares e as construções como tendo cada um deles seus espíritos animados; ao reconhecer a anima mundi - que todas as coisas são almadas, que têm intenções próprias, hábitos e prazeres próprios. Tratar as coisas com respeito e suas propriedades. Alquimia é animismo. Os materiais confiam que possamos melhorá-los. Nada pode ser usado sem sua cooperação consentida.

Ao tratar os materiais como almados, ao invocar os espíritos dos metais e ao falar de suas qualidades emocionais, a alquimia encontrou deuses na natureza, e alma, ou animação no mundo físico. (HILLMAN, 2010, p. 47)

O filósofo Eliade (1979) discorre sobre a extração de metais in natura e sobre as origens alquímicas na metalurgia, que trabalha com a transformação de metais por meio do contato com o fogo. Tal autor também aborda o reconhecimento dos alquimistas sobre as propriedades comuns entre os metais, que ao passarem por um processo podem se transformar. Nota-se que na passagem da visão inicial da metalurgia para a ciência moderna tem-se a aquisição de um tom "matemático", cercada por elementos como ligações, íons, diferente da visão alquímica que se articula com outras expressões, como de elementos comuns providos pela Mãe Terra ${ }^{5}$. Dessa forma, a Alquimia observava os deuses na natureza e uma animação no mundo físico como portadores de alma.

$O$ resgate do pensamento alquímico trata de enxergar que a cidade, o bairro, o prédio, a casa na qual está o setting terapêutico é provido de alma, possui interferência nas pessoas que estão ali. Reconhecer a anima mundi é reconhecer que o local no qual o paciente sonhou estar, esse que ele apresenta como sonho ou experiências reais, são providos de alma e merecem respeito, visto que possuem algum sentido para o indivíduo. Se provém de alguma imagem arquetípica, por que a expressão para tal momento possui maior energia psíquica? O fazer alma na terapia trata-se de compor tal encontro com esses elementos aos quais muitas vezes faltam palavras, mas não metáforas. Símbolos são invocados ao serem verbalizados quando um sonho é descrito e todos os elementos estruturais da Alquimia são possíveis de serem utilizados, como a metalurgia, a tintura, o fogo.

As diversas abordagens psicológicas referemse ao tempo de um processo terapêutico como relativo devido à singularidade de cada indivíduo, dentre outros fatores. Hillman (2010) apresenta o olhar alquímico sobre esse encontro, olhar que vai além do uso de metáforas. Neste sentido, se observarmos o processo de mudança da natureza através do calor, seja por vulcões ou pelas estações, bem como a manipulação do fogo observada em

\footnotetext{
${ }^{5} \mathrm{O}$ conceito alquímico de Mãe Terra indica que esta é "um ser que gesta metais, entendidos como organismos vivos em seu interior, compostos sempre dos mesmos elementos [...] Em seu ventre ficavam armazenados "embriões" metálicos - os minerais - que iam se desenvolvendo, amadurecendo e se transformando paulatinamente em diferentes metais, até alcançarem o aprimoramento maior" (LIMA; SILVA, 2003 p. 23)
} 
povos primitivos, notamos a metáfora do fogo como transformador. Silveira (2002) discorre sobre Jung em seu percurso ao qual estudou diversas áreas de conhecimento, bem como diversos povos, buscou ampliar seu contato com elementos do inconsciente coletivo e as similaridades estruturais entre estes elementos. Dessa forma, apresenta-se como consistente o fato do psicólogo conhecer outras questões para além de conceitos psicológicos, por assim evitar o "psicologismo do indivíduo", viabilizando que algumas expressões saiam do concretismo ao qual possam estar presas.

São essas relações entre significados e símbolos, ou em rituais similares entre povos que nunca tiveram contato, ou existiram em épocas diferente, que nos chama a atenção para a questão arquetípica. Essas são expressas de diferentes formas, porém são estruturalmente similares indicando o que está essencialmente no mundo e assim também no ser humano. Acredita-se, assim, que a questão arquetípica está presente no setting terapêutico e demanda atenção por parte do psicólogo.

O processo de contato com os símbolos também expresso na Alquimia nos traz a imagem de um laboratório de Alquimia, com recipientes em diversos formatos para suas diversas funções, processos que demandam aquecimento por fogo ou intermediado por outro elemento, como mencionado sobre o banho-maria. Tais recipientes também nos remetem ao formato dos recipientes ou vasos, são características de anima, como o arquétipo feminino, estando tanto no mundo quanto no indivíduo.

O vaso alquímico e o vaso hermético sempre significam o local em que se operam maravilhas; é o seio materno, o útero no qual se forma um novo nascimento. Daí vem a crença de que o vaso contém o segredo das metamorfoses.

O vaso encerra, sob diversas formas, o elixir da vida: é um reservatório de vida. Um vaso de ouro pode representar o tesouro da vida espiritual, o símbolo de uma força secreta.

O fato de o vaso ser aberto em cima indica uma receptividade às influências celestes. (GHEERBRANT; CHEVALIER, 2000, p. 929 - 930)

No que se refere aos vasos e recipientes, destaca-se o pelicano, um recipiente hermético utilizado na circulação de tinturas com função estruturalmente semelhante à imagem oriental do uroboro, a serpente que engole o próprio rabo. Hillman discorre, assim, sobre seu funcionamento:

\footnotetext{
A cabeça envia seu produto de volta para baixo, para o corpo, repetidamente. Acontece uma circulação contínua. O que sobe para a cabeça não escapa. À medida que a substância derrete, evapora, lançando vapores para cima, formam-se ideias nebulosas, a pressão aumenta, giram sentimentos leves e animadores. Mas essas inspirações e ideias quentes são reprocessadas e lançadas para baixo por serem muito imaturas, muito crua, ainda fora do ponto, muito irreais. Ao invés, são jogadas de volta no vaso para serem alimento novamente... Repetição. Iteratio: assim chamaram. "mas eu já vi isso!" "mas eu já fiz isso!" A mesma coisa repetidamente. (HILLMAN, 2010, p. 67)
}

Dessa forma o pelicano é um vaso sacrificial, assim como a ave que é conhecida por bicar o próprio peito para extrair sangue para poder alimentar seus filhotes, caso não consiga comida para eles. A similaridade do processo com o nome do recipiente, bem como o processo de tintura alquímica, nos remete a processos encontrados na clínica. Neste sentido, para observarmos os conceitos, acredita-se que basta imaginarmos o processo. Ideias nebulosas que aumentam a pressão, que retornam à origem em um processo, sendo esse o de separação dos elementos em busca de "purificação", ou seja, "processar" o que é "ruim". Para cada processo há um recipiente, por exemplo, o processo de decantação possui outras características de modo a viabilizar que os resíduos mais densos acumulem-se no fundo do reservatório. Sendo assim, cada recipiente é específico para cada momento do processo, a cada povo, a cada função. Podem, por exemplo, 
ser mais utilizados por uns do que por outros, de forma a expressar-se mais pelo feminino do que pelo masculino, ou vice-versa. Por isso os tratados alquímicos nunca poderiam ser exatos como a ciência contemporânea.

Diante deste cenário concebe-se que o psicólogo não deve agir com suas teorias como se fossem um fluxograma ou uma receita. Para além de considerar a subjetividade como justificativa para incertezas, entende-se o mundo como animado, no sentido de possuir alma. Nesta visão, o carvão não é unicamente uma árvore queimada, nem o fogo apenas uma reação física ou química, nem tão pouco os recipientes ou o vento.

No que se relaciona ao vento, este também possui o seu lugar na leitura arquetípica em relação ao sopro e múltiplas são as menções ao sopro, sendo conhecido como o princípio de vida. Ele é mencionado na Bíblia, no livro de Gênesis que indica que Deus sopra nas narinas do homem e ele passa a ser animado por uma alma viva. De acordo com os mulçumanos, o espírito é o sentido primeiro. Já para o Taoísmo, no início havia nove sopros e, por fim, no latim sopro é conhecido como anima, que para Jung é o arquétipo feminino. (GHEERBRANT; CHEVALIER, 2000).

Os símbolos e suas expressões estão no mundo e interagimos com eles, para além de uma manipulação de objetos, pois são objetos animados, como exposto, envolvidos por alma. Alma é a metáfora, assim como a palavra e o termo, que deixa de ser classificatório para ser imaginativo. Sendo de fato muitas questões demandadas nos atendimentos, torna-se impossível prever o que seja o fim do processo e quando o será. Sobre estas questões, as palavras de Hillman atingem um tom poético ao referir-se às qualidades do calor e da alma, pois fogem dos populares e por algumas vezes determinista tons dos conceitos psicológicos. Ao expressar-se com metáforas, retorna-se à investigação alquímica por ampliar a imaginação e evocar novas imagens, que auxiliam na compreensão dos complexos do paciente. Segundo Jung (2009), são imagens carregadas de afeto que circundam o núcleo de um complexo, dado o fato que a autonomia de um complexo pode possuir a pessoa, e não a pessoa possuindo um complexo, resultando assim em um estado patológico. O complexo, de acordo com Hillman (2010), é um estado de contato com o material inconsciente válido, pois é o que incomoda e chama a atenção para essas imagens.

A metáfora amplia a imaginação. A Psicologia Analítica é uma Psicologia politeísta, das imagens, da Alquimia, de revisões, um constante fazer, que não se encera em conclusões lógicas ou no "nominalismo" das palavras com o objeto. Assim como a poesia faz do verbo algo além da classificação gramatical, a terapia deve ir além das classificações no caminho das transformações, alquimicamente no caminho da transmutação, do passar pelo fogo, da cura como um processo, não como extinção "cirúrgica" de algo.

\section{Considerações Finais}

Considera-se que a construção de um conhecimento é extremamente importante para o campo científico. Trata-se de um encontro para se descrever o que ainda não foi descrito ou observado. Entende-se que a Psicologia mesmo que inicialmente tendo surgido das ciências médicas, e atravessada pelas ciências humanas, apropria-se de metáforas para dar forma aos conceitos. Assim como fez Freud com a Psicanálise, referindo-se à tragédia grega de Édipo, como fez Jung ao buscar mitos e símbolos, Hillman entende a contribuição desses pensadores como estrutura e não como regra, bem como propõe rever a sua posição diante disso. Percorre-se, assim, um caminho para a construção de um saber que promova um encontro significativo sobre a psique, de modo que a busca não deve ser por uma teoria que simplesmente nos identificamos, mas sim por algo 
que nos instiga a elaborar uma psicologia como resposta. Esse foi o caminho percorrido por Freud e por Jung transformando-os em psicólogos, esse deve ser o caminho para tornarmos psicólogos.

Trata-se de montar um quebra-cabeça sem estampa, no qual as peças principalmente das bordas possuem seu lugar, de forma que ao final tenhamos uma tela na qual possa-se estampar. Fazer Psicologia não trata de inventar novos conceitos e termos, mas sim possibilitá-la como agente transformador, promotor de encontros em um mergulho ao encontro da psique.

Por meio da leitura de Hillman sobre Psicologia Alquímica, observa-se um olhar para a Psicologia diferente do olhar de Jung para com a Alquimia, fato esse que não anula a contribuição dos estudos de Jung sobre Alquimia, mas apropria-se desse sem repeti-lo como regra, apresentando-nos como possibilidade de articulação no consultório.

O setting terapêutico mostra-se também como o lugar dos tópicos sinistros, aos quais por muitas vezes estes são apresentadas em metáforas. Em análise a pessoa se vê em um movimento de raciocínio diferente do seu modo de observar a si e ao mundo. Acaba assim por se deparar com outros que o habitam, que por vezes nunca se conheceram plenamente, cabendo ao indivíduo interpretá-los e traduzi-los (HILLMAN, 2009). $\mathrm{O}$ analista articula-se com tais tópicos na mesma linguagem em um processo que, assim como nos tratados alquímicos, trata-se de imagens. Defende-se uma postura do psicólogo diante disso, lembrando que a atitude do alquimista interfere diretamente no processo, postura esta, que implica em uma relação de almas, que só é possível se essas forem ouvidas e respeitadas, considerando o mundo como animado para poder ser imaginado. Se uma cadeira vermelha surge em sonho é porque essa cadeira quer algo com o sonhador. O que é o vermelho? O que é o convite a sentar-se? O que é a repulsa ou aceitação ao convite da cadeira?
Como Jung aponta como premissa da Psicologia Analítica, deve-se "ficar com a imagem". Para tal, deve-se ampliá-la com outras imagens e não interpretá-las ou dar um significado a elas, pois uma imagem com um significado perde sua função, esgota-se. Indica-se um movimento na terapia de maior entendimento possibilitado por novas imagens, que ampliam a energia dessa que se apresenta. Almeja-se, assim, ouvi-la e compreendê-la. Para tanto, é necessário que tanto o paciente, quanto o psicólogo, compreendam o "fazer-alma" (soul making), ou seja, possibilitar que a imagem não seja reduzida a conceitos. É conversar sobre a tal cadeira vermelha ao invés de, por exemplo, defini-la como um trono. As contribuições da mitologia, arte e Alquimia na Psicologia são para se ampliarem as possibilidades imaginais, não para classificá-las em um sentido único.

AAlquimia é uma forma de destilar, condensar, aquecer e transmutar os processos, ao que Jung encontrou similaridades estruturais entre Psicologia e Alquimia, com uma troca de saberes que promoveu o desenvolvimento da Psicologia Analítica. Esta se mostra, então, como uma Psicologia que foge de termos como junguianos e freudianos, que estuda as expressões arquetípicas e do indivíduo, que se apropria de saberes outros e não menos nem mais importantes, mas pertencentes ao mundo, à anima mundi. Hillman ao buscar o encontro com a Alquimia e atento a não repetir o que Jung já havia feito, propôs percorrer o caminho expressivo dos alquimistas de maneira a não seguir a um exercício da Psicologia que se limita a conceitos, mas que se dispõe aos processos. Hillman apropria-se da "poeisis" assim em seus textos e sua fala em tom poético a fim de "tocar" as imagens e fazer alma de forma contribuir para Psicologia e não atingir seguidores "hillmanianos". Frente a isso, cabe ao psicólogo estar sempre atento a sua prática para que a mesma não se resuma a métodos e diagnósticos, mas sim um serviço prestado não 
exclusivamente a um indivíduo, mas sim a alma, seja ela qual for.

\section{Referências}

ELIADE, M. Ferreiros e alquimistas. Rio de Janeiro: Zahar, 1979.

GHEERBRANT, A.; CHEVALIER, J. Dicionário de símbolos. Rio de Janeiro: J. Olympio, 2000.

HILlMAN, J. Anima: anatomia de uma noção personificada. São Paulo: Cultrix, 1995.

2011.

. Psicologia alquímica. Petrópolis: Vozes,

. Re-vendo a psicologia. Petrópolis: Vozes, 2010.

. Suicídio e alma. Petrópolis: Vozes, 2009.

JUNG, C. G. Ab-reação, análise dos sonhos, transferência. Petrópolis: Vozes, 1990. (Obras completas, v. 16, n. 2).

2009.

. A natureza da psique. Petrópolis: Vozes,

. Estudos alquímicos. Rio de Janeiro: Nova

Fronteira, 1975.

. Cartas de C. G Jung. Petrópolis: Vozes, 2002. v. 2, 1946-1955.

- Memórias, sonhos e reflexões. Rio de Janeiro: Nova Fronteira, 1975.

- O desenvolvimento da personalidade.

Petrópolis: Vozes, 1981.

. Os arquétipos e o inconsciente coletivo.

Petrópolis: Vozes, 2002.

1991
LIMA, T. A.; SILVA, M. N. Alquimia, ocultismo, maçonaria: o ouro e o simbolismo hermético dos cadinhos (Séculos XVIII e XIX). Anais do Museu Paulista [online], São Paulo, v. 8-9, n. 1, p. 9-54, 2001. Disponível em: <http://www.scielo. $\mathrm{br} / \mathrm{scielo} . \mathrm{php}$ ? script $=\mathrm{sci}$ arttext\&pid $=\mathrm{S} 0101$ $47142001000100002 \& \operatorname{lng}=$ en\&nrm $=$ iso $>$. Acesso em: 1 maio 2015.

LOSEE, J. Introdução histórica da filosofia da ciência. Lisboa: Terramar, 1998.

READ, J. Alchemy and alchemists. Nature, London, v. 168, p. $759-762,1951$.

SILVEIRA, N. Jung: vida e obra. Rio de Janeiro: Paz e Terra, 2002.

WILHELM, R; JUNG, C. G. O segredo da flor de ouro. Petrópolis: Vozes, 1977. 